\title{
Percepção dos servidores públicos de um centro de pesquisas sobre aspectos da qualidade de vida no trabalho
}

\author{
Perception of public servants of a centre on research aspects of quality \\ of life at work
}

\author{
1 Estefânia Câmara Santos Lopes estefania.lopes@cpqrr.fiocruz.br \\ 2 Marismary Horsth de Seta
}
1 Mestre em Saúde Pública pela Escola Nacional de Saúde Pública (ENSP); Tecnologista em Saúde Pública do Centro de Pesquisas René Rachou (CPqRR) - Fiocruz/MG.
2 Doutorado e Mestrado em Saúde Coletiva pela Universidade do Estado do Rio de Janeiro. Tecnologista Sênior do Departamento de Administração e Planejamento em Saúde da ENSP/FIOCRUZ.

\section{Resumo}

Nesta pesquisa, objetivou-se conhecer a percepção que os servidores públicos de um centro de pesquisas têm em relação a aspectos relacionadas à Qualidade de Vida no Trabalho (QVT). Utilizando-se de questões extraídas do instrumento proposto por Ferreira (2009), o IA_QVT (Inventário de Avaliação de Qualidade de Vida no Trabalho), disponibilizou-se um questionário em meio eletrônico para atribuição de notas, através de uma escala tipo Likert, quanto às assertivas relacionadas aos fatores estruturantes da QVT propostos pelo autor. Esses fatores são: Condições de Trabalho, Organização do Trabalho, Relações Socioprofissionais de Trabalho, Reconhecimento e Crescimento Profissional e Elo Trabalho - Vida Social. Houve participação de 67 servidores (46,21\% dos convidados). Os resultados demonstraram que há pontos favoráveis e desfavoráveis à QVT em cada um dos fatores, elucidando a necessidade de atuação institucional com propostas de melhorias sobre aqueles desfavoráveis e fortalecimento dos favoráveis.

\section{Palavras-chave}

qualidade de vida no trabalho; servidor público; centro de pesquisa.

\begin{abstract}
This study aimed to know the perception that public servants of a research center is in relation to aspects related to the Quality of Life at Work (QVT). Using the extracted issues of the instrument proposed by Ferreira (2009), IA_QVT (Inventory of Quality of Life Assessment at Work), provided a questionnaire electronically for grading, using a Likert scale, as the statements related to structural factors of QWL proposed by the author. These factors are: Working Conditions, Labour Organization, Working socio-professional Relations, Recognition and Professional Growth and Elo Work-life social. There was participation of 67 servers $(46.21 \%$ of the guests). The results showed that there are favorable and unfavorable points to QVT in each of the factors, elucidating the need for institutional action with improvement proposals on those unfavorable and strengthening favorable.
\end{abstract}

\section{Keywords}

quality of life at work; public servants; centre on research.

\section{Como você deve citar?}

LOPES, Estefânia Câmara Santos; DE SETA, Marismary Horsth. Percepção dos servidores públicos de um centro de pesquisas sobre aspectos da qualidade de vida no trabalho. Cadernos UniFOA, Volta Redonda, n. 33, p. 87-98, abr. 2017. 


\section{INTRODUÇÃO}

Mudanças na economia mundial, nas relações sociais e políticas, no desenvolvimento da tecnologia e na organização produtiva desencadearam um ambiente de competitividade entre as organizações de todo o mundo. (ALBUQUERQUE e FRANÇA, 1998; ABRAHÃO e PINHO, 2002).

Nesse contexto, recai sobre o trabalhador exigência quanto ao investimento em capital intelectual, maior comprometimento organizacional, participação criadora, mobilização da subjetividade, capacidade de diagnosticar e de decidir, maior intervenção nos processos produtivos, desempenho, alcance de metas e resultados, maior qualificação e atualização de suas habilidades, flexibilização quanto à agregação de novas tarefas e da funcionalidade, valorizando-se a polivalência e a politecnia. (ABRAHÃO e PINHO, 2002; ANDRADE e VEIGA, 2012; FERREIRA, ALVES e TOSTES, 2009; ROCHA e FERNANDES, 2008; VASCONCELOS, 2001). Porém, ao mesmo tempo que aumentam as cobranças quanto à produtividade e qualidade (VASCONCELOS, 2001; ABRAHÃO e PINHO, 2002; REGO, 2008; FERREIRA, ALVES e TOSTES, 2009), pode não haver condições para o desenvolvimento do trabalho e precauções, como a preservação da saúde e segurança do trabalhador, na mesma proporção. (ALBUQUERQUE e FRANÇA, 1998).

Semelhante ao que ocorre na esfera privada, no setor público, esse contexto histórico e social cobra por agilidade, produz novos padrões de competitividade intermediados pelo uso de alta tecnologia, aumenta a exigência quanto à proatividade. Para Filho (2004), os servidores públicos vivenciam a intensificação do trabalho, as formas de racionalização presentes no setor público, a cobrança dos cidadãos que estão mais conscientes de seus direitos e impacientes com o funcionalismo público e, soma-se a precariedade das condições de trabalho, caracterizada pela insuficiência e inadequação de espaços e equipamentos. Além disso, especialmente na área da saúde, os profissionais convivem com o desafio da busca por soluções de novos e antigos problemas que assolam a população.

Nessa perspectiva, evidencia-se a responsabilidade que as Instituições Públicas de Saúde têm em aliar o desenvolvimento, considerando suas particularidades e em promover Qualidade de Vida no Trabalho (QVT). O tema Qualidade de Vida no Trabalho tem crescido em importância, uma vez que busca harmonizar, tanto quanto possível, as necessidades e a relação entre trabalho, trabalhadores e instituições.

É importante salientar que QVT não pode ser vista como a solução para todos os males institucionais (PADILHA, 2009), mas sim, um caminho possível de construção em prol do equilíbrio entre bem-estar, produção, eficiência e efıcácia, por meio da identificação e de esforços que minimizem fontes de mal-estar presentes no trabalho, e de fortalecimento daqueles elementos que a favoreçam (FERREIRA, 2012; MEDEIROS e FERREIRA, 2011).

Práticas promotoras da QVT que considerem o bem-estar dos servidores, a satisfação dos usuários-cidadãos, a eficiência e eficácia do trabalho prestado são, portanto, desafios às organizações públicas. Ferreira et al. (2009) afırmam que os programas de QVT têm uma relevância social, pois propiciam melhorias à QVT dos servidores públicos, o que repercute na produtividade organizacional e, portanto, contribuem para o exercício da cidadania dos clientes (cidadãos) dessas instituições.

Quanto a QVT no serviço público, Ferreira, Alves e Tostes (2009) dizem que apesar dos debates sobre o tema terem crescido nos últimos anos, as práticas que são desenvolvidas no serviço público ainda são pouco exploradas. "Se no setor privado a temática QVT tem historicamente maior inserção e presença, no setor público ela permanece uma questão incipiente e um campo científico de interesse restrito." (FERREIRA apud FERREIRA, ALVES e TOSTES, 2009, p. 319). 
Assim, este estudo foi realizado visando contribuir na identificação dos elementos percebidos pelos servidores públicos como sendo favoráveis ou desfavoráveis à vivência da QVT em uma Instituição Pública de Pesquisa em Saúde, contribuindo para a elaboração de medidas que a promovam, identificando a percepção dos servidores públicos sobre os aspectos que a ela se relacionam.

\section{MATERIAIS E MÉTODOS}

Foram convidados a participar da pesquisa os servidores públicos efetivos, tanto da área da gestão quanto da pesquisa, lotados no Centro de Pesquisas René Rachou (CPqRR), unidade da Fiocruz, em Belo Horizonte/ MG, excluindo-se os que não estavam exercendo atividades regularmente na Instituição. Elegeu-se esse grupo de trabalhadores pela necessidade de avaliar a percepção dos servidores permanentes, visto que gozam da possibilidade de estabilidade na instituição, em um contexto de mudanças na esfera pública.

Aos servidores que atendiam aos critérios de inclusão (145 dos 156 lotados na Instituição) enviou-se um convite para participar da pesquisa, através do e-mail previamente cadastrado na plataforma de Educação à Distância da Escola Nacional de Saúde Pública (EAD/ENSP) e, destes, 67 (46,21\%) participaram efetivamente. Também, durante a coleta de dados, divulgou-se cartazes nos murais e na página inicial da Intranet, objetivando explicar a forma e o prazo para participação e os contatos da pesquisadora, em caso de dúvidas.

O questionário continha 45 assertivas extraídas das 61 que compõem o Inventário de Avaliação de Qualidade de Vida no Trabalho (IA_QVT), elaborado por Ferreira (2009), desenvolvido para diagnóstico e monitoramento de QVT nas organizações, que busca identificar a QVT por meio das representações dos trabalhadores sobre o contexto organizacional onde estão inseridos. As questões selecionadas buscaram aproximar-se de questões mais perceptíveis quanto a realidade da Instituição e a maior adesão pela redução do tempo de preenchimento.

Para as assertivas apresentadas, os servidores deveriam atribuir notas por meio de uma escala tipo Likert, compreendida entre 0 a 10, sendo que o intervalo zero significava a discordância total, e dez, a concordância total, sobre os cinco fatores estruturantes da QVT propostos pelo autor, demonstrados em seguida no Quadro 1. 
Quadro 1 - Fatores estruturantes da QVT e características

\begin{tabular}{|l|l|}
\hline Fator & Características \\
\hline Condições de Trabalho & $\begin{array}{l}\text { Expressa as condições físicas (local, espaço, iluminação, temperatura), } \\
\text { materiais (insumos), instrumentais (equipamentos, mobiliário, posto), suporte } \\
\text { (apoio técnico) que influenciam a atividade de trabalho e colocam em risco a } \\
\text { segurança física do trabalhador. }\end{array}$ \\
\hline Organização do Trabalho & $\begin{array}{l}\text { Expressa as variáveis de tempo (prazo, pausa), controle (fiscalização, pressão, } \\
\text { cobrança), traços das tarefas (ritmo, repetição, sobrecarga e prescrição } \\
\text { (normas) que influenciam a atividade de trabalho. }\end{array}$ \\
\hline Relações Socioprofissionais de Trabalho & $\begin{array}{l}\text { Expressa as interações socioprofissionais em termos de relações com os } \\
\text { pares (ajuda, harmonia, confiança), com as chefias (liberdade, diálogo, acesso, } \\
\text { interesse, cooperação, atribuição e conclusão de tarefas), comunicação } \\
\text { (liberdade de expressão), ambiente harmonioso e conflitos que influenciam a } \\
\text { atividade de trabalho. }\end{array}$ \\
\hline Reconhecimento e Crescimento \\
Profissional & $\begin{array}{l}\text { Expressa variáveis relativas ao reconhecimento no trabalho (existencial, } \\
\text { institucional, realização profissional, dedicação, resultado alcançado) e ao } \\
\text { crescimento profissional (oportunidade, incentivos, equidade, criatividade, } \\
\text { desenvolvimento) que influenciam a atividade de trabalho. }\end{array}$ \\
\hline Elo Trabalho - Vida Social & $\begin{array}{l}\text { Expressa as percepções sobre a instituição, o trabalho (prazer bem-estar, zelo, } \\
\text { tempo passado no trabalho, sentimento de utilidade, reconhecimento social) } \\
\text { e as analogias com a vida social (casa, família, amigos) que influenciam a } \\
\text { atividade de trabalho. }\end{array}$ \\
\hline
\end{tabular}

Fonte: Ferreira, 2012

As respostas às assertivas foram analisadas dentro de cada fator ao qual pertenciam, identificando-se as avaliações favoráveis e desfavoráveis à QVT, de acordo com a porcentagem relativa e o número absoluto dos respondentes sobre a pontuação atribuída na escala Likert.

Considerou-se que, na escala Likert, o valor cinco representava o ponto neutro de concordância na gradação e os valores acima de 6 implicaram em algum grau de concordância, sinalizando a percepção favorável para a QVT; para os valores abaixo de 4, uma percepção desfavorável, exceto para nove questões que apresentavam essa interpretação inversa. São elas: Fator Condições de Trabalho: "O trabalho que realizo coloca em risco a minha segurança física". Fator Organização do Trabalho: "Há cobrança de prazos para o cumprimento das tarefas"; "Falta tempo para ter pausa de descanso no trabalho"; "As normas para execução das tarefas são rígidas"; "O ritmo de trabalho é excessivo"; "No CPqRR existe forte cobrança por resultados"; Fator Relações Socioprofissionais do Trabalho: "A comunicação entre funcionários é insatisfatória"; "É comum a não conclusão de trabalhos iniciados"; "É comum o conflito no ambiente de trabalho" .

As respostas obtidas e armazenadas, codificadas através da plataforma EAD/ENSP que abrigou o questionário, foram convertidas do Sistema Avaliação On-Line para uma tabela de Excel ${ }^{\text {R }}$.

O projeto foi aprovado nos Comitês de Ética em Pesquisa (CEP) da Escola Nacional de Saúde Pública Sergio Arouca (ENSP) e do CPqRR, recebendo o número do Certificado de Apresentação para Apreciação Ética (CAAE) 28574914.9.0000.5240 e 28574914.9.3001.5091, respectivamente.

\section{RESULTADOS E DISCUSSÃO}

Os resultados obtidos são referentes aos valores cumulativos atribuídos pelo quantitativo de servidores nos pontos da escala Likert, de acordo com suas percepções sobre as assertivas em cada um dos fatores. As figuras evidenciam as valorações, sendo que o ponto 5 representa o ponto de 
neutralidade em relação a cada assertiva. À sua esquerda, encontra-se demonstrada a discordância com a assertiva e, à sua direita, a concordância. Os números em cada pergunta correspondem ao do questionário aplicado.

\subsection{Fator Condições de Trabalho}

O fator Condições de Trabalho objetiva verificar como os servidores percebem as condições físicas, instrumentais, materiais e de suporte no contexto de trabalho (FERREIRA, 2012). Dez itens compuseram o questionário referente a esse fator.

Figura 1 - Valoração (cumulativa) atribuída a cada uma das assertivas do Fator Condições de Trabalho

\begin{tabular}{|c|c|c|c|c|c|c|}
\hline \multirow{2}{*}{$\begin{array}{l}\text { Responda de forma sincera às afirmativas } \\
\text { apresentadas abaixo, M arque na escala que } \\
\text { vaide } 0 \text { (zero) a } 10 \text { (dez) referentea sua } \\
\text { opinião sobre cada itemapresentado, } 0 \\
\text { (zero) representa a discordanciatotal o } 10 \\
\text { (dez) a concordânciatotal. }\end{array}$} & \multicolumn{2}{|c|}{$0-4$} & \multicolumn{2}{|c|}{5} & \multicolumn{2}{|c|}{$6-10$} \\
\hline & $\mathbf{n}$ & $\%$ & $\mathbf{n}$ & $\%$ & $\mathbf{n}$ & $\%$ \\
\hline \multicolumn{7}{|c|}{ FA TOR CONDIÇÕES DE TRABALHO } \\
\hline $\begin{array}{l}\text { 2) O nivel de lum Inaçäo é suficıente para executar } \\
\text { as atividades }\end{array}$ & 6 & $8,95 \%$ & 8 & $11,94 \%$ & 53 & $79,10 \%$ \\
\hline 8)O local de trabalho é confortável & 28 & $41,80 \%$ & 10 & $14,93 \%$ & 29 & $43,28 \%$ \\
\hline 14) O material de consumo é suficiente & 6 & $8,95 \%$ & 7 & $10,45 \%$ & 54 & $80,60 \%$ \\
\hline 16) O espaço físico é satisfatório & 42 & $62,69 \%$ & 7 & $10,45 \%$ & 18 & $26,87 \%$ \\
\hline $\begin{array}{l}\text { 22) O apo } 10 \text { técnıco para as atıvıdades é } \\
\text { suficiente }\end{array}$ & 21 & $31,34 \%$ & 12 & $17,91 \%$ & 34 & $50,75 \%$ \\
\hline $\begin{array}{l}\text { 31) U mobiliárıo existente no local de trabalho è } \\
\text { adequado }\end{array}$ & 28 & $41,80 \%$ & 10 & $14,93 \%$ & 29 & $43,28 \%$ \\
\hline $\begin{array}{l}\text { 35) O trabalho que realızo coloca em risco a } \\
\text { minha segurança física }\end{array}$ & 40 & $59,70 \%$ & 8 & $11,94 \%$ & 19 & $28,36 \%$ \\
\hline $\begin{array}{l}\text { 39) Us instrumentos de trabalho säo suticientes e } \\
\text { adequados para realizar as tarefas }\end{array}$ & 14 & $20,90 \%$ & 10 & $14,93 \%$ & 43 & $64,18 \%$ \\
\hline 42) A temperatura ambiente é confortável & 31 & $46,27 \%$ & 7 & $10,45 \%$ & 29 & $43,28 \%$ \\
\hline $\begin{array}{l}\text { 45) O posto de trabalho è adequado para a } \\
\text { realização das tarefas }\end{array}$ & 23 & $33,33 \%$ & 11 & $16,42 \%$ & 33 & $49,25 \%$ \\
\hline
\end{tabular}

Os resultados apontam que o provimento de materiais de consumo e instrumentos, a segurança para desempenho do trabalho e a iluminação adequada devem ser mantidos e consolidados na Instituição, visando à QVT. Merece alerta por estar dividindo opiniões, a adequação do posto de trabalho para realização das tarefas, o provimento do apoio técnico, o conforto do local de trabalho, a temperatura e a adequação do mobiliário.

Sobre a satisfação quanto ao espaço físico, necessita-se de intervenções e deve ser modificado, pois está mal avaliado, quanto à QVT. É importante destacar que a Instituição tem passado por transformações na estrutura física para absorver o quantitativo de trabalhadores, alunos e equipamentos que têm crescido ao longo do tempo, o que, frequentemente, culmina na necessidade de reformulação de espaços, nem sempre adequados para o desempenho das atividades de trabalho, o que pode ter refletido na avaliação dos servidores.

Dejours (2011, p. 66) explica que as condições de trabalho inadequadas podem gerar sentimento de medo no trabalhador, o que pode comprometer a saúde mental. Pacheco (2011) relata que condições de trabalho são um dos principais pilares de avaliações dentro do contexto organizacional e que, se inadequados, podem gerar sentimento de mal-estar relacionado ao trabalho. 


\subsection{Fator Organização do Trabalho}

Nesse fator, avaliam-se elementos relativos ao controle e traços das tarefas, normas, sobrecarga e variáveis de tempo, como prazos e pausas (FERREIRA, 2012, p. 184). Sete itens compuseram a análise desse fator.

Figura 2 - Valoração (cumulativa) atribuída a cada uma das assertivas do Fator Organização do Trabalho

\begin{tabular}{|c|c|c|c|c|c|c|}
\hline \multirow{2}{*}{$\begin{array}{l}\text { Responda de forma sincera às afirmativas apresentadas } \\
\text { abaixo, M arque na escala que vai de } 0 \text { (zero) a } 10 \text { (dez) } \\
\text { referente a sua opinião sobre cada item apresentado, } 00 \\
\text { (zero) representa a discordância total e o } 10 \text { (dez) a } \\
\text { concordância total. }\end{array}$} & \multicolumn{2}{|c|}{$0-4$} & \multicolumn{2}{|c|}{5} & \multicolumn{2}{|c|}{$6-10$} \\
\hline & $\mathbf{n}$ & $\%$ & $\mathbf{n}$ & $\%$ & $\mathbf{n}$ & $\%$ \\
\hline \multicolumn{7}{|c|}{ FAT OR ORGA NIZAÇÃ O DO TRABALHO } \\
\hline 5) Há cobrança de prazos para o cumprimento das tarefas & 6 & $8,95 \%$ & 8 & $11,94 \%$ & 53 & $79,10 \%$ \\
\hline 23) Posso executar o meu trabalho sem sobrecarga de tarefas & 27 & $40,30 \%$ & 5 & $7,46 \%$ & 35 & $52,24 \%$ \\
\hline 27) Falta tempo para ter pausa de descanso no trabalho & 40 & $59,70 \%$ & 9 & $13,43 \%$ & 18 & $26,87 \%$ \\
\hline 30) As normas para execução das tarefas são rígidas & 21 & $31,34 \%$ & 11 & $16,42 \%$ & 35 & $52,24 \%$ \\
\hline 33) O ritmo de trabalho é excessivo & 30 & $44,78 \%$ & 9 & $13,43 \%$ & 28 & $41,80 \%$ \\
\hline 41) No CPqRR existe forte cobrança por resultados & 14 & $20,90 \%$ & 9 & $13,43 \%$ & 44 & $65,67 \%$ \\
\hline 44) Posso executar o meu trabalho sem pressão & 18 & $26,87 \%$ & 8 & $11,94 \%$ & 41 & $61,19 \%$ \\
\hline
\end{tabular}

A pressão percebida para a execução do trabalho e a existência de tempo para realização de pausas são itens que apresentam resultados favoráveis à QVT e devem ser mantidos e aprimorados.

A rigidez nas normas para execução das tarefas, a excessividade no ritmo de trabalho e a sobrecarga de tarefas dividem opiniões e servem de alerta. Garcia (2007) reflete que a sobrecarga no serviço público pode ocorrer, devido à falta de compromisso e acomodação de alguns trabalhadores reforçados pela conveniência de algumas chefias com a situação.

Quanto à cobrança de prazos no cumprimento das tarefas e por resultados demonstram ser fatores que têm impactado negativamente na percepção dos servidores sobre a QVT, indicando que devem ser modificados.

Os resultados encontrados podem estar relacionados ao papel da instituição, uma vez que a Fiocruz é uma instituição de referência nacional e internacional e o nível de cobrança por resultados e no cumprimento de prazos pode ser elevado, visando cumprir exigências internas e externas e manter um padrão de qualidade satisfatório, podendo ter gerado reflexos na percepção da QVT dos servidores.

Apesar da pressão no trabalho ter sido bem avaliada, conforme demonstrado, os elementos que apresentaram avaliações desfavoráveis à QVT podem ser causadores de pressão no trabalho e consequente sobrecarga, indicando que se não se atuar sobre eles, os índices mais favoráveis também podem sofrer impactos negativos futuros.

Quanto à rigidez nas normas para execução das tarefas, Ferreira e Mendes (2001) alertam que a padronização e a minimização da capacidade criativa no trabalho são fontes de sofrimento do trabalhador. Esses autores citam pesquisas que mostram que o medo e o tédio provocam sofrimentos manifestos na forma de ansiedade e insatisfação; a mecanização e robotização da tarefa, a pressão e imposição que advém da organização do trabalho são também fontes de sofrimento. 
Evidenciou-se que, apesar de a maioria perceber a existência de cobrança quanto aos resultados e prazos, são bons os índices de concordância sobre haver tempo para pausa de descanso no trabalho e execução do trabalho sem pressão, sendo a sobrecarga, a rigidez nas normas para execução das tarefas e o ritmo de trabalho excessivo sentidos, sem que se configure como altamente desfavorável à QVT.

\subsection{Fator Relações Socioprofissionais de Trabalho}

Por meio desse fator, são avaliadas as relações com os pares e chefias, a harmonia e a presença de conflitos no ambiente de trabalho e as possibilidades de expressão no contexto de trabalho (FERREIRA, 2012, p. 184). Doze itens compuseram a análise desse fator.

Figura 3 - Valoração (cumulativa) atribuída a cada uma das assertivas do Fator Relações Socioprofissionais de Trabalho

\begin{tabular}{|c|c|c|c|c|c|c|}
\hline \multirow{2}{*}{$\begin{array}{c}\text { Responda de forma sincera às afirmativas } \\
\text { apresentadas abaixo, M arque na escala que vai de } \\
0 \text { (zero) a } 10 \text { (dez) referente a sua opinião sobre } \\
\text { cada item apresentado, o } 0 \text { (zero) representa a } \\
\text { discordância total e o } 10 \text { (dez) a concordância } \\
\text { total. }\end{array}$} & \multicolumn{2}{|c|}{$0-4$} & \multicolumn{2}{|c|}{5} & \multicolumn{2}{|c|}{$6-10$} \\
\hline & $\mathbf{n}$ & $\%$ & $\mathbf{n}$ & $\%$ & $\mathbf{n}$ & $\%$ \\
\hline \multicolumn{7}{|c|}{ FATOR RELA ÇÕES SOCIOPROFISSIONAIS DE TRABALHO } \\
\hline $\begin{array}{l}\text { 4)M eus colegas de trabalho demonstram disposiçäo em me } \\
\text { ajudar }\end{array}$ & 8 & $11,94 \%$ & 2 & $2,99 \%$ & 57 & $85,07 \%$ \\
\hline $\begin{array}{l}\text { 9)M inhas relaçöes de trabalho com os colegas säo } \\
\text { harmoniosas }\end{array}$ & 3 & $4,48 \%$ & 4 & $5,97 \%$ & 60 & $89,55 \%$ \\
\hline 2) M inhas relações de trabalho com a chefia são cooperativas & 2 & $2,99 \%$ & 3 & $4,48 \%$ & 62 & $92,54 \%$ \\
\hline ß3) Tenho liberdade na execução das tarefas & 5 & $7,46 \%$ & 5 & $7,46 \%$ & 57 & $85,07 \%$ \\
\hline 26) A convivência no ambiente de trabalho é harmoniosa & 6 & $8,95 \%$ & 2 & $2,99 \%$ & 59 & $88,06 \%$ \\
\hline 28) A distribuição das tarefas é justa & 18 & $26,87 \%$ & 5 & $7,46 \%$ & 44 & $65,67 \%$ \\
\hline $\begin{array}{l}\text { 32) No CP qRR, tenho liberdade para dizer o que penso sobre o } \\
\text { trabalho }\end{array}$ & 14 & $20,90 \%$ & 8 & $11,94 \%$ & 45 & $67,16 \%$ \\
\hline 36) A comunicação entre funcionários é insatisfatória & 25 & $37,3 \%$ & 8 & $11,94 \%$ & 34 & $50,75 \%$ \\
\hline 37) No CP qRR, tenho livre acesso às chefias superiores & 8 & $11,94 \%$ & 4 & $5,97 \%$ & 55 & $82,09 \%$ \\
\hline 38) É comum a não conclusão de trabalhos iniciados & 35 & $52,24 \%$ & 4 & $5,97 \%$ & 28 & $41,80 \%$ \\
\hline 40) Éfácil o acesso à chefia imediata & 3 & $4,48 \%$ & 4 & $5,97 \%$ & 60 & $89,55 \%$ \\
\hline 43) É comum o conflito no ambiente de trabalho & 35 & $52,24 \%$ & 12 & $17,91 \%$ & 20 & $29,85 \%$ \\
\hline
\end{tabular}

Os itens desse fator, de um modo geral, foram os mais bem avaliados, dentre os cinco fatores analisados.

Os resultados mostram que são aspectos favoráveis à vivência da QVT a facilidade e a liberdade de acesso, bem como a relação de trabalho com as chefias, a harmonia nas relações e na convivência no trabalho, a disposição em ajudar por parte dos colegas e a liberdade na execução das tarefas, demonstrando serem estes, aspectos a serem mantidos e consolidados na Instituição.

Quanto à percepção sobre a existência de conflitos no trabalho, a não conclusão de trabalhos iniciados e a comunicação insatisfatória entre funcionários, há divisão nas opiniões, sendo que o primeiro reuniu o maior número de participantes (17,91\%), nesse fator, no valor cinco, ou seja, de neutralidade da escala. Sendo assim, representam estado de alerta e necessitam de intervenção, visando prevenir que esses aspectos sejam fontes de mal-estar no trabalho e, portanto, prejudiciais à QVT.

Sobre a comunicação entre funcionários, Ferreira (2012) analisa que é um facilitador nas relações de trabalho, pois representa a abertura do diálogo. 
Assim, tendo em vista que os servidores, devido à prerrogativa da efetividade, têm a possibilidade de passar longos anos na Instituição convivendo com um mesmo grupo de trabalhadores, é necessário que se envidem esforços para que a percepção favorável atribuída para a maioria dos itens relativos a esse fator seja mantida. Para isso, é importante atuar sobre as causas que ainda dividem opiniões, minimizando as fontes de conflitos no trabalho, melhorando a comunicação e compreendendo a causa da não finalização de alguns trabalhos.

\subsection{Fator Reconhecimento e Crescimento Profissional}

Esse fator, que avalia elementos relacionados ao reconhecimento no trabalho como a dedicação, 0 alcance de resultados, a realização profissional e também ao crescimento profissional como incentivos, oportunidades e equidade (FERREIRA, 2012, p. 184), foi composto por nove itens.

Figura 4 - Valoração (cumulativa) atribuída a cada uma das assertivas do Fator Reconhecimento e Crescimento Profissional

\begin{tabular}{|c|c|c|c|c|c|c|}
\hline \multirow{2}{*}{$\begin{array}{c}\text { Responda de forma sincera às } \\
\text { afirmativas apresentadas abaixo, } \\
\text { M arque na escala que vai de } 0 \text { (zero) a } \\
10 \text { (dez) referente a sua opinião sobre } \\
\text { cada item apresentado, o } 0 \text { (zero) } \\
\text { representa a discordância total e o } 10 \\
\text { (dez) a concordância total. }\end{array}$} & \multicolumn{2}{|c|}{$0-4$} & \multicolumn{2}{|c|}{5} & \multicolumn{2}{|c|}{$6-10$} \\
\hline & $\mathbf{n}$ & $\%$ & $\mathbf{n}$ & $\%$ & $\mathbf{n}$ & $\%$ \\
\hline \multicolumn{7}{|c|}{ FATOR RECONHECIMENTO E CRESCIMENTO PROFISSIONAL } \\
\hline $\begin{array}{l}\text { 3)O reconhecimento do trabalho individual é } \\
\text { uma prática efetiva no CPqRR }\end{array}$ & 20 & $29,85 \%$ & 13 & $19,4 \%$ & 34 & $50,75 \%$ \\
\hline $\begin{array}{l}\text { 6)As oportunidades de crescimento } \\
\text { pro fissional são iguais para todos }\end{array}$ & 28 & $41,80 \%$ & 12 & $17,9 \%$ & 27 & $40,30 \%$ \\
\hline $\begin{array}{l}\text { 7)Tenho a possibilidade de ser criativo no meu } \\
\text { trabalho }\end{array}$ & 9 & В,43\% & 8 & $11,94 \%$ & 50 & $74,63 \%$ \\
\hline $\begin{array}{l}\text { 10) O reconhecimento do trabalho coletivo é } \\
\text { uma prática efetiva no CPqRR }\end{array}$ & 18 & $26,87 \%$ & 10 & $14,93 \%$ & 39 & $58,21 \%$ \\
\hline $\begin{array}{l}\text { 11) O CP qRR o ferece oportunidade de } \\
\text { crescimento profissional }\end{array}$ & 16 & $23,88 \%$ & 5 & $7,46 \%$ & 46 & $68,66 \%$ \\
\hline $\begin{array}{l}\text { 17) O desenvolvimento pessoal é uma } \\
\text { possibilidade real no CPqRR }\end{array}$ & 18 & $26,87 \%$ & 10 & $14,93 \%$ & 39 & $58,21 \%$ \\
\hline $\begin{array}{l}\text { 20) Há incentivos do CPqRR para o } \\
\text { crescimento na carreira }\end{array}$ & 20 & $29,85 \%$ & 5 & $7,46 \%$ & 42 & $62,69 \%$ \\
\hline $\begin{array}{l}\text { 25) No CPqRR minha dedicação ao trabalho é } \\
\text { reconhecida }\end{array}$ & 2 & $17,91 \%$ & 9 & \3,43\% & 46 & $68,66 \%$ \\
\hline $\begin{array}{l}\text { 34) No CPqRR, recebo inc entivos de minha } \\
\text { chefia }\end{array}$ & 14 & $20,90 \%$ & 5 & $7,46 \%$ & 48 & $71,64 \%$ \\
\hline
\end{tabular}

Apresentaram avaliações favoráveis à QVT a possibilidade de ser criativo no trabalho, as oportunidades e o incentivo ao crescimento profissional, inclusive por parte da chefia, a possibilidade do desenvolvimento pessoal e o reconhecimento do trabalho coletivo e da dedicação ao trabalho, sendo os itens que devem ser mantidos e consolidados.

O item "O reconhecimento do trabalho individual é uma prática efetiva no CPqRR" demonstrou opiniões divididas e também foi mais mal avaliado do que o quesito reconhecimento do trabalho coletivo, mostrando ser esse um fator de alerta que necessita de intervenção, visando à QVT.

Também dividiu opiniões a igualdade nas oportunidades de crescimento, indicando a necessidade de haver modificações, visando à QVT. Para Ferreira (2012), oportunidade e igualdade são dois pilares que balizam o sentido que crescimento profissional assume para os trabalhadores, sendo a igualdade fundamental, para não haver obstáculos nas possibilidades de crescimento profissional. 


\subsection{Fator Elo Trabalho - Vida Social}

Esse fator, composto por sete itens, agrega elementos que se relacionam à percepção sobre o trabalho e à instituição e às analogias com a vida social como casa, amigos e família (FERREIRA, 2012, p. 184).

Figura 5 - Valoração (cumulativa) atribuída a cada uma das assertivas do Fator Elo Trabalho - Vida Social

\begin{tabular}{|c|c|c|c|c|c|c|}
\hline \multirow{2}{*}{$\begin{array}{c}\text { Responda de forma sincera às } \\
\text { afirmativas apresentadas abaixo, } \\
\text { M arque na escala que vai de } 0 \text { (zero) a } 10 \\
\text { (dez) referente a sua opinião sobre cada } \\
\text { item apresentado, o } 0 \text { (zero) representa } \\
\text { a discordância total e o } 10 \text { (dez) a } \\
\text { concordância total. }\end{array}$} & \multicolumn{2}{|c|}{$0-4$} & \multicolumn{2}{|c|}{5} & \multicolumn{2}{|c|}{$6-10$} \\
\hline & $\mathbf{n}$ & $\%$ & $\mathbf{n}$ & $\%$ & $\mathbf{n}$ & $\%$ \\
\hline \multicolumn{7}{|c|}{ FATOR ELO TRABALHO VIDA SOCIAL } \\
\hline $\begin{array}{l}\text { 1)No CP qRR, as atividades que realizo são fonte } \\
\text { de prazer }\end{array}$ & 11 & $16,42 \%$ & 8 & $11,94 \%$ & 48 & $71,64 \%$ \\
\hline $\begin{array}{l}\text { 15) Sinto que o meu trabalho no CPqRR me faz } \\
\text { bem }\end{array}$ & 11 & $16,42 \%$ & 6 & $8,95 \%$ & 50 & $74,63 \%$ \\
\hline $\begin{array}{l}\text { 18) No CP qRR dis po nho de tempo para executar o } \\
\text { meu trabalho com zelo }\end{array}$ & 6 & $8,95 \%$ & 7 & $10,45 \%$ & 54 & $80,60 \%$ \\
\hline 19) Go sto da instituição onde trabalho & 2 & $2,99 \%$ & 4 & $5,97 \%$ & 61 & $91,04 \%$ \\
\hline $\begin{array}{l}\text { 21) A so ciedade reconhece a importancia do meu } \\
\text { trabalho }\end{array}$ & 13 & $19,40 \%$ & 16 & $23,88 \%$ & 38 & $56,72 \%$ \\
\hline $\begin{array}{l}\text { 24) O tempo de trabalho que passo no CP qRR me } \\
\text { faz feliz }\end{array}$ & 13 & $19,40 \%$ & 12 & $17,91 \%$ & 42 & $62,69 \%$ \\
\hline 29) O trabalho que faço é útil para a sociedade & 9 & $13,43 \%$ & 3 & $4,48 \%$ & 55 & $82,09 \%$ \\
\hline
\end{tabular}

Os itens do Fator Elo Trabalho - Vida Social apresentaram, de modo geral, boa avaliação dos respondentes. Dos sete itens, seis foram classificados com pontuação superior ao valor seis da escala por mais de $60 \%$ dos respondentes, demostrando concordância. Também, o item mais bem avaliado "Gosto da instituição onde trabalho", com 91,04\% dos respondentes nesse ponto da escala, foi o segundo mais bem avaliado de todo o questionário em termos de porcentagens de respondentes que apresentaram níveis de concordância.

Sem dúvida, a percepção positiva sobre essa assertiva é um bom indício para a avaliação da QVT. Gostar do local de trabalho, apesar de todos os pontos que necessitam de melhoria, demostra que os servidores, de uma forma geral, tem sentimento de bem-estar com relação à Instituição.

0 item que apresentou o menor percentual de participantes, atribuindo valores acima de 6 na escala, mas que, ainda assim, reuniu mais da metade de servidores, demonstrando ser um item com uma avaliação favorável, foi "A sociedade reconhece a importância do meu trabalho", com $56,72 \%$, o que aponta que mesmo que o reconhecimento social deixe a desejar, o servidor reconhece a importância do seu trabalho para essa mesma sociedade, como evidenciado no item "O trabalho que faço é útil para a sociedade", com 82,09\% dos participantes, apresentando concordância acima de 6 na escala.

Garcia (2007) identificou que o quesito orgulho do serviço prestado foi um dos itens mais bem avaliados entre os funcionários públicos avaliados em seu estudo, sendo também bem avaliado o orgulho de ser funcionário público. No entanto, acredita-se que os profissionais ainda sofrem com rótulos sobre a imagem, que não é positiva no país.

A maioria dos participantes evidenciou sentimento de gostar e de se sentir feliz na instituição, de ter tempo para executar com zelo as tarefas e serem elas fontes de prazer e de bem-estar e de 
reconhecerem a importância do seu trabalho para a sociedade, apesar de não haver tanto sentimento do reconhecimento por parte dela. Portanto, são itens favoráveis à QVT e que devem ser mantidos e consolidados.

\section{CONSIDERAÇÕES FINAIS}

A análise mostra que os elementos percebidos como mais favoráveis à QVT referem-se, predominantemente, a itens do fator Relações Socioprofissionais no Trabalho e Elo Trabalho-Vida Social. Destacam-se as relações de cooperação e de facilidade de acesso junto às chefias, gostar da instituição, a harmonia nas relações, na convivência no ambiente de trabalho e a disponibilidade dos colegas em ajudar, a liberdade para execução das tarefas, o sentimento de utilidade do seu trabalho para a sociedade, a disponibilidade de tempo para executar as tarefas com zelo e de material de consumo.

De forma intermediária, evidenciando haver divisão nas opiniões e, portanto, sendo necessário atuar em melhorias, predominaram itens relacionados ao fator Condições de Trabalho como o conforto do local de trabalho, a temperatura, a adequação do mobiliário e do posto de trabalho e o apoio técnico para as atividades.

Os itens avaliados de forma mais desfavorável foram inferiores, se comparados aos itens favoráveis à QVT. Destaca-se a cobrança de prazos para o cumprimento das tarefas e também a forte cobrança por resultados, ambos relacionados ao Fator Organização do Trabalho e a insatisfação quanto ao espaço físico, relacionada ao fator Condições de Trabalho, evidenciando serem essas as prioridades, quanto às ações em prol da QVT.

Demonstra-se que fatores favoráveis e desfavoráveis coexistem na vivência à QVT dos servidores. É necessário que haja um esforço para atuação sobre aqueles desfavoráveis, objetivando mudá-los, e que se fortaleçam os favoráveis, propiciando melhorias à Qualidade de Vida no Trabalho.

Espera-se que o estudo auxilie na identificação, por parte das Instituições Públicas, principalmente, os centros de pesquisa em saúde, quanto aos elementos prioritários para a vivência à QVT, tendo-se como base a percepção dos próprios sujeitos que nelas atuam.

\section{AGRADECIMENTO}

A Educação à Distância da Escola Nacional de Saúde Pública Sérgio Arouca (CDEAD/ENSP) pelo uso da plataforma e do Sistema de Avaliação On line. 


\section{REFERÊNCIAS}

ABRAHAO, Júlia Issy; PINHO, Diana Lúcia Moura. As transformações do trabalho e desafios teóricometodológicos da Ergonomia. Estud. psicol. (Natal), Natal, v. 7, n. spe, 2002, p. 45-52. Disponível em: $<$ http://www.scielo.br/scielo.php?script=sci_arttext\&pid=S1413-294X2002000300006 $>$. Acesso em: 13 nov. 2013.

ALBUQUERQUE, L. G.; FRANÇA, A. C. L. Estratégias de Recursos Humanos e gestão da qualidade de vida no trabalho: o stress e a expansão do conceito de qualidade total. Revista de Administração, São Paulo, v. 33, n. 2, abr./jun. 1998, p. 40-51. Disponível em: <http://www.rausp.usp.br/busca/artigo. asp?num_artigo=144>. Acesso em: 20 nov. 2013.

ANDRADE, Polyanna Peres; VEIGA, Heila Magali da Silva. Avaliação dos trabalhadores acerca de um programa de qualidade de vida no trabalho: validação de escala e análise qualitativa. Psicol. cienc. prof., Brasília, v. 32, n. 2, 2012, p. 304-319. Disponível em: <http://www.scielo.br/scielo.php?script=sci_ arttext\&pid=S1414-98932012000200004>. Acesso em: 13 nov. 2013.

DEJOURS, Christophe. Da psicopatologia à psicodinâmica do trabalho. 3. ed., rev. ampl. Rio de Janeiro: Ed. Fiocruz; 2011, 507 p.

FERREIRA R.R. et al. Concepção e Implantação de um Programa de Qualidade de Vida no Trabalho (PQVT) no Setor Público: o Papel Estratégico dos Gestores. Revista Administração, São Paulo, v. 44, n. 2, abr./mai/jun. 2009, p. 147-157. Disponível em: <www.rausp.usp.br/download.asp?file=V4402147. pdf $>$. Acesso em: 23 out. 2014.

FERREIRA M.C, ALVES L, TOSTES N. Gestão da Qualidade de Vida no Trabalho (QVT) no Serviço Público Federal: o Descompasso entre Problemas e Práticas Gerenciais. Psicologia: Teoria e Pesquisa, v. 25, n. 3, jul./ set. 2009, p. 319-327. Disponível em: <http://www.ergopublic.com.br/arquivos/1260303872.08arquivo.pdf>. Acesso em: 20 out. 2013.

FERREIRA, M.C. Inventário de Avaliação de Qualidade de Vida no Trabalho. Instrumento de Diagnóstico e Monitoramento de QVT nas Organizações [internet]. In: Anais da $61^{\text {a }}$ Reunião da Sociedade Brasileira para o Progresso da Ciência; 2009; Manaus, Amazonas, Brasil. Manaus: Sociedade Brasileira para o Progresso da Ciência; 2009, [acesso 27 Out 2014]. Disponível em <http://www.sbpcnet.org.br/livro/61ra/ resumos/resumos/5473.htm>. Acesso em: 27 de out. 2013.

FERREIRA, M.C.; MENDES, A.M. "Só de pensar em vir trabalhar, já fico de mau humor": atividade de atendimento ao público e prazer-sofrimento no trabalho. Estudos de Psicologia (Natal), Natal, v.6, n. 1, jan./ jun. 2001. Disponível em: <http://www.scielo.br/scielo.php?pid=S1413-294X2001000100010\&script=sci_ arttext>. Acesso em: 23 out. 2014.

FERREIRA, Mário César. Qualidade de Vida no Trabalho. Uma abordagem centrada no olhar dos trabalhadores. 2. ed., Editora Paralelo 15, Brasília, 2012.

FILHO, José Marçal Jackson. Desenho do trabalho e patologia organizacional: um estudo de caso no serviço público. Revista Produção, São Paulo, v.14, n.3, set./dez. 2004, p. 58-66. Disponível em: <http:// www.scielo.br/scielo.php?script=sci_arttext\&pid=S0103-65132004000300007>. Acesso em: 28 out. 2013. 
GARCIA, Edilene de Oliveira Pereira. Qualidade de Vida no Trabalho: com a palavra os funcionários públicos. 2007, 185 p. Dissertação (Mestrado em Administração) - Universidade Metodista de São Paulo. São Bernardo do Campo.

MEDEIROS L, F, R.; FERREIRA M, C. Qualidade de Vida no trabalho: uma revisão da produção científica de 1995-2009. Revista Gestão Contemporânea, Porto Alegre, ano 8, n.9, jan./jun. 2011, p. 9-34. Disponível em: <http://www.ergopublic.com.br/arquivos/1359565902.29-arquivo.pdf $>$. Acesso em: 22 nov. 2013.

PACHECO, Veruska Albuquerque. Qualidade de Vida no Trabalho, Bem-estar e Mal-estar sob a Ótica de Trabalhadores de uma Agência Reguladora no Brasil. 2011. 134 f. Dissertação (Mestrado em Psicologia) - Universidade de Brasília, Brasília. Disponível em: <http://www.ergopublic.com.br/ arquivos/1360931827.95-arquivo.pdf $>$. Acesso em: 10 ago. 2013.

PADILHA, Valquíria. Qualidade de Vida no Trabalho num cenário de precarização: a panaceia delirante. Trabalho, Educação e Saúde, Rio de Janeiro, v.7, n.3, nov. 2009, p. 549-563. Disponível em: <http://www. scielo.br/scielo.php?pid=S1981-77462009000300009\&script=sci_arttext $>$. Acesso em: 10 ago. 2013.

REGO, R.M. Expressão artística e Teleatendimento: perspectivas para melhoria de Qualidade de Vida no Trabalho. Psicologia, Ciência e Profissão, Brasília, v. 28, n. 1, 2008, p. 200-209. Disponível em: <http:// www.scielo.br/scielo.php?pid=S1414-98932008000100015\&script=sci_arttext $>$. Acesso em: 20 out. 2013.

ROCHA, V.M, da; FERNANDES, M.H. Qualidade de vida de professores do ensino fundamental: uma perspectiva para a promoção da saúde do trabalhador. Jornal Brasileiro de Psiquiatria, Rio de Janeiro, v. 57, n.1, 2008, p. 23-27. Disponível em: <http://www.scielo.br/scielo.php?script=sci_ arttext\&pid=S0047-20852008000100005>. Acesso em: 20 out. 2013.

VASCONCELOS, A.F. Qualidade de vida no Trabalho: origem, evolução e perspectivas. Caderno de Pesquisas em Administração, São Paulo, v. 8, n. 1, jan./ mar. 2001, p. 23-35. Disponível em: <http:// www.ead.fea.usp.br/cad-pesq/arquivos/v08-1art03.pdf >. Acesso em: 12 out. 2013. 